\title{
18-Hydroxydolabella-3,7-diene synthase - a diterpene synthase from Chitinophaga pinensis
}

\author{
Jeroen S. Dickschat ${ }^{*}$, Jan Rinkel ${ }^{1}$, Patrick Rabe ${ }^{1}$, Arman Beyraghdar Kashkooli $^{2}$ \\ and Harro J. Bouwmeester ${ }^{3}$
}

\section{Full Research Paper}

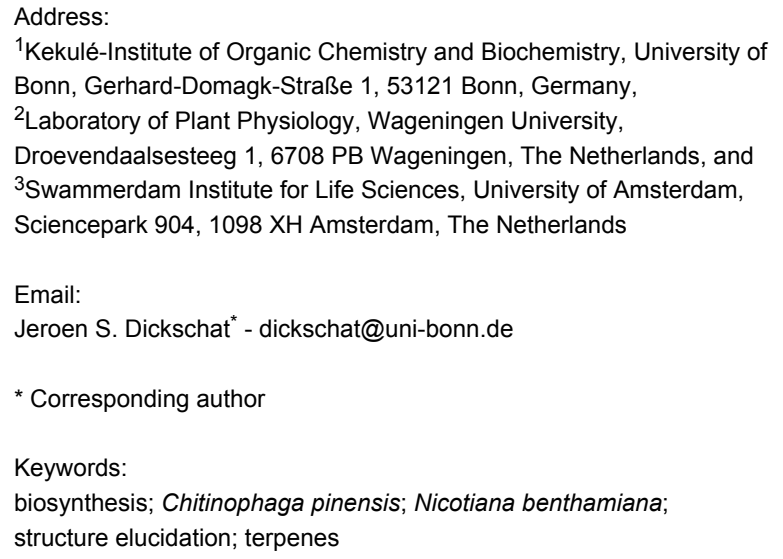

${ }^{1}$ Kekulé-Institute of Organic Chemistry and Biochemistry, University of Bonn, Gerhard-Domagk-Straße 1, 53121 Bonn, Germany,

2Laboratory of Plant Physiology, Wageningen University,

Droevendaalsesteeg 1, 6708 PB Wageningen, The Netherlands, and

${ }^{3}$ Swammerdam Institute for Life Sciences, University of Amsterdam,

Sciencepark 904, 1098 XH Amsterdam, The Netherlands

Email:

Jeroen S. Dickschat ${ }^{*}$ - dickschat@uni-bonn.de

${ }^{*}$ Corresponding author

\section{Keywords:}

biosynthesis; Chitinophaga pinensis; Nicotiana benthamiana;

structure elucidation; terpenes

Beilstein J. Org. Chem. 2017, 13, 1770-1780.

doi:10.3762/bjoc. 13.171

Received: 21 June 2017

Accepted: 09 August 2017

Published: 23 August 2017

This article is part of the Thematic Series "Lipids: fatty acids and derivatives, polyketides and isoprenoids".

Associate Editor: A. Kirschning

(C) 2017 Dickschat et al.; licensee Beilstein-Institut.

License and terms: see end of document.

\begin{abstract}
The product obtained in vitro from a diterpene synthase encoded in the genome of the bacterium Chitinophaga pinensis, an enzyme previously reported to have germacrene A synthase activity during heterologous expression in Escherichia coli, was identified by extensive NMR-spectroscopic methods as 18-hydroxydolabella-3,7-diene. The absolute configuration of this diterpene alcohol and the stereochemical course of the terpene synthase reaction were addressed by isotopic labelling experiments. Heterologous expression of the diterpene synthase in Nicotiana benthamiana resulted in the production of 18-hydroxydolabella-3,7-diene also in planta, while the results from the heterologous expression in $E$. coli were shown to be reproducible, revealing that the expression of one and the same terpene synthase in different heterologous hosts may yield different terpene products.
\end{abstract}

\section{Introduction}

Terpene synthases convert a handful of simple linear and achiral oligoprenyl diphosphates in just one enzymatic step into a remarkable diversity of usually polycyclic structurally complex lipophilic terpenes with multiple stereogenic centres. In their active sites type I terpene synthases contain the highly conserved aspartate-rich motif $\operatorname{DDXX}(\mathrm{X})(\mathrm{D}, \mathrm{E})$ and the NSE triad NDXXSXX(R,K)(E,D), modified to a DTE triad in plants, for binding of the $\mathrm{Mg}^{2+}$ cofactor that forms a trinuclear $\left(\mathrm{Mg}^{2+}\right)_{3}$ cluster to which the diphosphate portion of the substrate binds. Upon substrate binding the active site closes, resulting in hydrogen bonds between the substrate's diphosphate and the pyrophosphate sensor, a highly conserved arginine located 
43 amino acids upstream of the NSE triad, and the RY dimer, a highly conserved motif at the C-terminus. The substrate is ionised by extrusion of diphosphate, yielding a highly reactive allyl cation that can react in a cyclisation cascade by attack of olefinic double bonds to the cationic centre, hydride shifts and Wagner-Meerwein rearrangements. The process is usually terminated by deprotonation or attack of water to yield a lipophilic terpene hydrocarbon or alcohol. Among the first investigated terpene synthases were the $(+)$ - and (-)-bornyl diphosphate synthases from the plants Salvia officinalis and Tanacetum vulgare forming a more polar product by the unusual termination via reattack of diphosphate [1], the trichodiene synthase from the fungus Trichothecium roseum [2], and pentalenene synthase from Streptomyces exfoliatus [3]. Recently, the first terpene synthases were reported from a eukaryotic soil microorganism, the social amoeba Dictyostelium discoideum [4,5]. With respect to bacterial enzymes, many terpene synthases have been identified and their products have been structurally characterised (reviewed in [6], following reports: [7-14]). One possible method to investigate the products of terpene synthases is the expression of terpene synthase genes in a heterologous host, as was recently performed for a large number of bacterial enzymes in an engineered Streptomyces avermitilis strain from which the biosynthesis genes for all other natural products were deleted, allowing a relatively easy purification of the terpene synthase products from culture extracts $[15,16]$. The heterologous expression of terpene synthase genes in Escherichia coli is also frequently successful, resulting in the production of volatile terpenes by this bacterium that can be detected in headspace extracts $[17,18]$. In one of these previous reports [17] we have described a terpene synthase from Chitinophaga pinensis DSM 2588 (accession number WP_012789469) as a sesquiterpene synthase for germacrene A (1), which was based on the identification of this compound and its Cope rearrangement product $\beta$-elemene (2) formed by the thermal impact during GC-MS analysis [19] in E. coli headspace extracts under heterologous expression of the terpene synthase gene (Scheme 1). Here we present the diterpene synthase activity of this enzyme in in vitro experiments and the first heterologous expression of a bacterial terpene synthase gene in a plant, Nicotiana benthamiana.

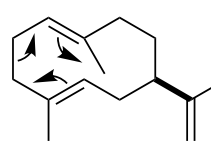

1
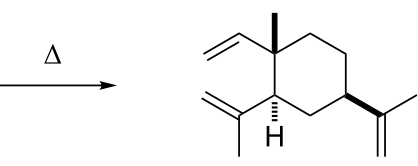

2
Scheme 1: Germacrene A (1) and its Cope rearrangement to $\beta$-elemene (2).

\section{Results and Discussion Characterisation of a diterpene synthase from Chitinophaga pinensis in vitro}

The terpene synthase from $C$. pinensis was heterologously expressed in $E$. coli as a recombinant protein with a C-terminal polyhistidine tag using a previously reported pET28c-based expression construct [17] and purified by Ni-NTA affinity chromatography (Figure S1, Supporting Information File 1). The purified enzyme was tested in in vitro experiments for mono-, sesqui- and diterpene activity by incubation with geranyl (GPP), farnesyl (FPP) and geranylgeranyl diphosphate (GGPP) as substrates, which yielded a single product 3 only from GGPP, but no products from FPP and GPP as demonstrated by GC-MS analysis (Figure 1). The mass spectrum of $\mathbf{3}$ showed a molecular ion at $m / z=290$ pointing to a diterpene alcohol and a base peak ion at $m / z=59$ indicative of a 2-hydroxyisopropyl group that frequently occurs in terpene alcohols. Both findings, i.e., no production of sesquiterpenes from FPP in in vitro experiments with recombinant purified enzyme as well as the emission of sesquiterpenes by $E$. coli during heterologous expression, were fully reproducible (Figure S2, Supporting Information File 1).

The compound 3 obtained from the in vitro incubation of GGPP was purified and its structure was elucidated by extensive oneand two-dimensional NMR spectroscopic methods (Table 1, Figures S3-S9, Supporting Information File 1). The ${ }^{13} \mathrm{C}$ NMR spectrum showed five signals for methyl groups, seven aliphatic $\mathrm{CH}_{2}$ groups, two aliphatic and two olefinic $\mathrm{CH}$ groups, and four signals for quarternary carbons including one connected to oxygen and two olefinic carbons, suggesting the structure of a bicyclic diterpene alcohol. The ${ }^{1} \mathrm{H},{ }^{1} \mathrm{H}-\mathrm{COSY}$ spectrum revealed three contiguous spin systems for $\mathrm{C} 2-\mathrm{C} 3, \mathrm{C} 5-\mathrm{C} 6-\mathrm{C} 7$, and C9-C10-C11-C12-C13-C14 (Scheme 2). Key HMBC correlations from $\mathrm{H} 19$ and $\mathrm{H} 20$ to $\mathrm{C} 12$ and $\mathrm{C} 18$ placed the 2-hydroxyisopropyl group at $\mathrm{C} 12$, while $\mathrm{HMBC}$ correlations from $\mathrm{H} 17$ to $\mathrm{C} 6, \mathrm{C} 7, \mathrm{C} 8$ and $\mathrm{C} 9$ located the $\mathrm{C} 8-\mathrm{C} 17$ fragment between $\mathrm{C} 7$ and $\mathrm{C}$. HMBC crosspeaks between $\mathrm{H} 16$ and $\mathrm{C} 3, \mathrm{C} 4$ and $\mathrm{C} 5$ indicated the $\mathrm{C} 3-\mathrm{C} 4-\mathrm{C} 5$ connection, and $\mathrm{HMBC}$ correlations between $\mathrm{H} 15$ and $\mathrm{C} 1, \mathrm{C} 2$ and $\mathrm{C} 14$, and between $\mathrm{H} 11, \mathrm{C} 1$ and $\mathrm{C} 2$ established the bonds between the quarternary carbon $\mathrm{C} 1$ and its four neighbours. Diagnostic NOESY correlations between H11 and $\mathrm{H} 2 \beta, \mathrm{H} 3$ and $\mathrm{H} 7$, between $\mathrm{H} 12$ and $\mathrm{H} 2 \beta$, and between $\mathrm{H} 10 \alpha$ and $\mathrm{H} 15$ established the relative configuration of $\mathbf{3}$, resulting in the structure of $\left(1 R^{*}, 3 E, 7 E, 11 S^{*}, 12 S^{*}\right)$-18-hydroxydolabella-3,7-diene and identifying the terpene synthase from $C$. pinensis as 18-hydroxydolabella-3,7-diene synthase (HdS).

The proposed cyclisation mechanism from GGPP to 3 is likely a concerted one-step process with 1,11- and 10,14-cyclisation and concomittant attack of water at C15 (Scheme 2). We have 
A)

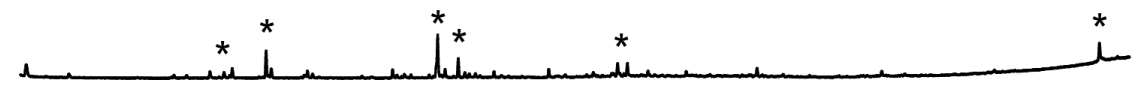

B)

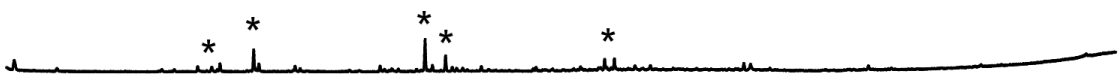

C) 3

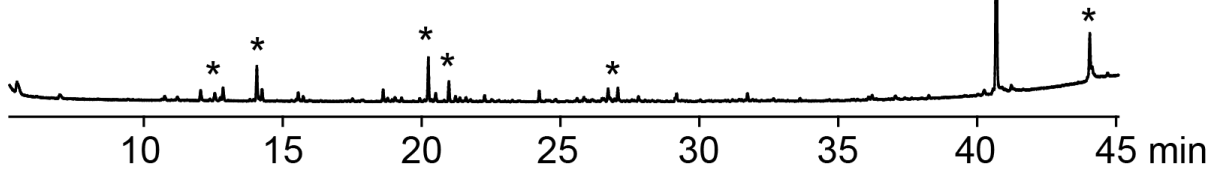

D)

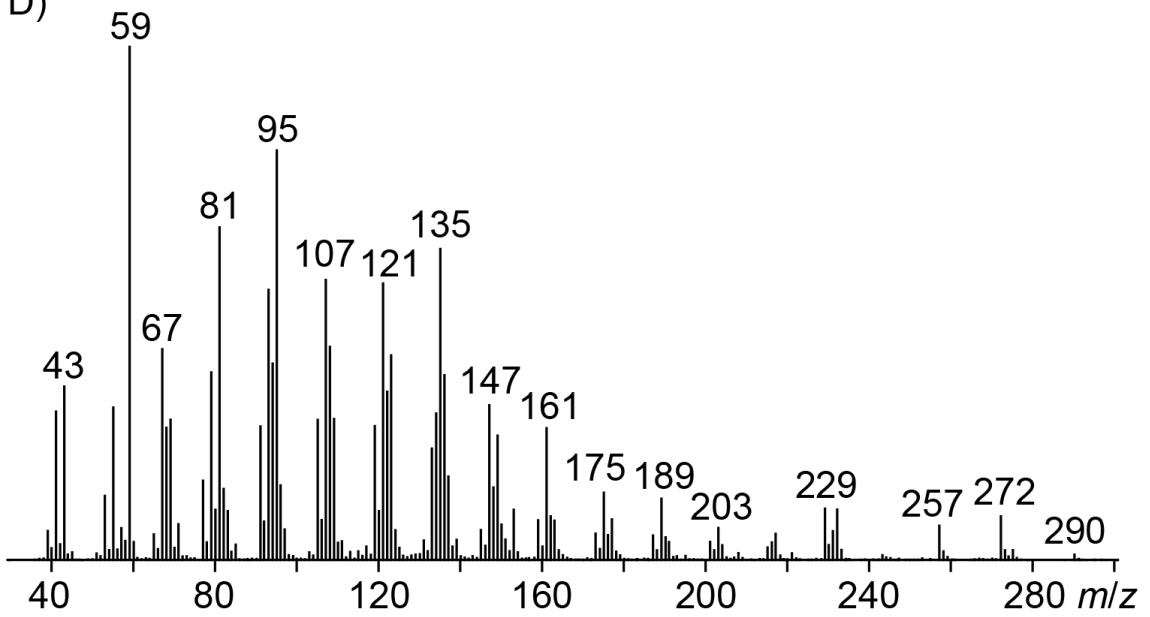

Figure 1: In vitro terpene synthase activity of the investigated recombinant enzyme from $C$. pinensis, showing no formation of monoterpenes from GPP (A) and no formation of sesquiterpenes from FPP (B), but formation of a single diterpene alcohol 3 from GGPP (C) with the mass spectrum depicted in (D). Asterisks indicate non-terpenoid contaminants such as plasticisers.

recently shown that the absolute configurations of terpenes can be determined by enzymatic conversion of stereoselectively deuterated terpene precursors, because the problem of determining the absolute configuration of the terpene under investigation is simplified to a problem of delineating the relative ori- entation of its stereocentres to the known absolute configuration at the deuterated carbon $[12,13]$. This approach was used to determine the absolute configuration of $\mathbf{3}$ using both enantiomers of $(R)$ - and $(S)-\left(1-{ }^{13} \mathrm{C}, 1-{ }^{2} \mathrm{H}\right) \mathrm{GGPP}[14],(R)$ - and $(S)-(1-$ $\left.{ }^{13} \mathrm{C}, 1-{ }^{2} \mathrm{H}\right) \mathrm{FPP}$, and $(R)-$ and $(S)-\left(1-{ }^{13} \mathrm{C}, 1-{ }^{2} \mathrm{H}\right) \mathrm{GPP}[12]$ in which 


\begin{tabular}{|c|c|c|}
\hline $\mathrm{C}^{\mathrm{a}}$ & ${ }^{13} \mathrm{C}(\delta)^{\mathrm{b}}$ & ${ }^{1} \mathrm{H}(\delta, \mathrm{m}, J, \text { int })^{\mathrm{C}}$ \\
\hline 1 & $47.5\left(\mathrm{C}_{\mathrm{q}}\right)$ & - \\
\hline 2 & $42.6\left(\mathrm{CH}_{2}\right)$ & $\begin{array}{l}2.19(\mathrm{~m}, 1 \mathrm{H}, \mathrm{H} \beta) \\
1.71(\mathrm{dd}, J=6.2, J=13.8,1 \mathrm{H}, \mathrm{H \alpha})\end{array}$ \\
\hline 3 & $126.5(\mathrm{CH})$ & $5.16(\mathrm{dd}, J=9.7, J=5.8,1 \mathrm{H})$ \\
\hline 4 & $134.0\left(\mathrm{C}_{\mathrm{q}}\right)$ & - \\
\hline 5 & $40.2\left(\mathrm{CH}_{2}\right)$ & $\begin{array}{l}2.12(\mathrm{~m}, 1 \mathrm{H}) \\
2.06(\mathrm{~m}, 1 \mathrm{H})\end{array}$ \\
\hline 6 & $25.0\left(\mathrm{CH}_{2}\right)$ & $\begin{array}{l}2.22(\mathrm{~m}, 1 \mathrm{H}, \mathrm{H} \beta) \\
2.05(\mathrm{~m}, 1 \mathrm{H}, \mathrm{H \alpha})\end{array}$ \\
\hline 7 & $128.2(\mathrm{CH})$ & $4.87(\mathrm{dd}, J=10.0, J=4.3,1 \mathrm{H})$ \\
\hline 8 & $134.0\left(\mathrm{C}_{\mathrm{q}}\right)$ & - \\
\hline 9 & $39.2\left(\mathrm{CH}_{2}\right)$ & $\begin{array}{l}2.27(\mathrm{~m}, 1 \mathrm{H}, \mathrm{H \alpha}) \\
2.14(\mathrm{~m}, 1 \mathrm{H}, \mathrm{H} \beta)\end{array}$ \\
\hline 10 & $23.7\left(\mathrm{CH}_{2}\right)$ & $\begin{array}{l}2.13(\mathrm{~m}, 1 \mathrm{H}, \mathrm{H} \beta) \\
1.23(\mathrm{~m}, 1 \mathrm{H}, \mathrm{H \alpha})\end{array}$ \\
\hline 11 & $42.1(\mathrm{CH})$ & $1.84(\mathrm{~m}, 1 \mathrm{H})$ \\
\hline 12 & $53.7(\mathrm{CH})$ & $1.84(\mathrm{ddd}, J=10.4, J=7.4, J=7.4,1 \mathrm{H})$ \\
\hline 13 & $26.0\left(\mathrm{CH}_{2}\right)$ & $\begin{array}{l}1.53(\mathrm{~m}, 1 \mathrm{H}) \\
1.53(\mathrm{~m}, 1 \mathrm{H})\end{array}$ \\
\hline 14 & $41.3\left(\mathrm{CH}_{2}\right)$ & $\begin{array}{l}1.47(\mathrm{~m}, 1 \mathrm{H}, \mathrm{H \alpha}) \\
1.39(\mathrm{~m}, 1 \mathrm{H}, \mathrm{H} \beta)\end{array}$ \\
\hline 15 & $24.9\left(\mathrm{CH}_{3}\right)$ & $1.08(\mathrm{~s}, 3 \mathrm{H})$ \\
\hline 16 & $16.6\left(\mathrm{CH}_{3}\right)$ & $1.59(\mathrm{~s}, 3 \mathrm{H})$ \\
\hline 17 & $16.0\left(\mathrm{CH}_{3}\right)$ & $1.47(\mathrm{~s}, 3 \mathrm{H})$ \\
\hline 18 & $72.1\left(\mathrm{C}_{\mathrm{q}}\right)$ & - \\
\hline 19 & $30.8\left(\mathrm{CH}_{3}\right)$ & $1.11(\mathrm{~s}, 3 \mathrm{H})$ \\
\hline 20 & $30.7\left(\mathrm{CH}_{3}\right)$ & $1.18(\mathrm{~s}, 3 \mathrm{H})$ \\
\hline
\end{tabular}

${ }^{a}$ Carbon numbering as shown in Scheme 2 . ${ }^{b}$ Chemical shifts $\delta$ in ppm and assignment of carbons by ${ }^{13} \mathrm{C}$-DEPT135 spectroscopy. ${ }^{c}$ Chemical shifts $\delta$ in ppm, multiplicity $\mathrm{m}(\mathrm{s}=$ singlet, $\mathrm{d}=$ doublet, $\mathrm{t}=$ triplet, $\mathrm{m}=$ multiplet), coupling constants $\mathrm{J}$ are given in Hertz.

A)

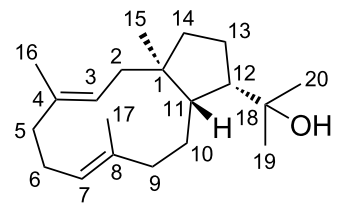

3

B)

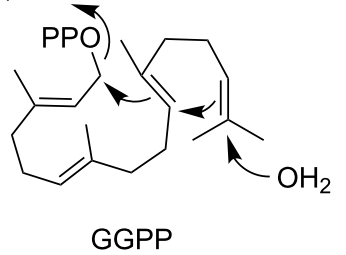

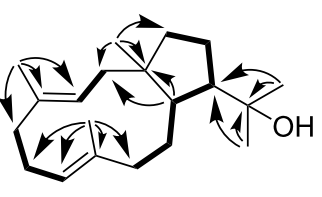

HdS<smiles>CC1=CC[C@]2(C)CC[C@@H](C(C)(C)O)[C@H]2CCC2=CCCC=C2C1</smiles>

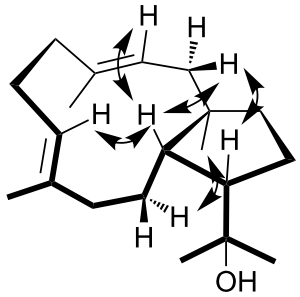

C)<smiles>CC1=CC[C@@H]2C(=CCC1)CC=C(C)CC[C@@H]2C(C)(C)O</smiles>

1,11-di-epi-3

Scheme 2: Product obtained from the diterpene synthase from C. pinensis. (A) Structure of (1R,3E,7E,11S,12S)-18-hydroxydolabella-3,7-diene (3), contiguous ${ }^{1} \mathrm{H},{ }^{1} \mathrm{H}$-COSY spin systems (bold), and diagnostic HMBC and NOESY correlations (single and double headed arrows). (B) Cyclisation mechanism for the conversion of GGPP into 3 by HdS. (C) Structure of the known stereoisomer 1,11-di-epi-3. 
the additional ${ }^{13} \mathrm{C}$ labels were introduced to increase sensitivity in the HSQC analysis of the obtained terpene products. Incubation of $(R)-\left(1-{ }^{13} \mathrm{C}, 1-{ }^{2} \mathrm{H}\right) \mathrm{GGPP}$ with HdS resulted in the specific incorporation of the deuterium labelling into the $2 \alpha$ position as indicated by a deminished crosspeak in the HSQC spectrum, while the crosspeak for $\mathrm{H} 2 \beta$ was strongly enhanced because of the ${ }^{13} \mathrm{C}$ labelling of $\mathrm{C} 2$ (Figure 2). Consistently, the substrate $(S)-\left(1-{ }^{13} \mathrm{C}, 1-{ }^{2} \mathrm{H}\right)$ GGPP gave a product with specific incorporation of the deuterium label into the $2 \beta$ position. Assuming inversion of configuration at $\mathrm{C} 1$ for the cyclisation of GGPP to

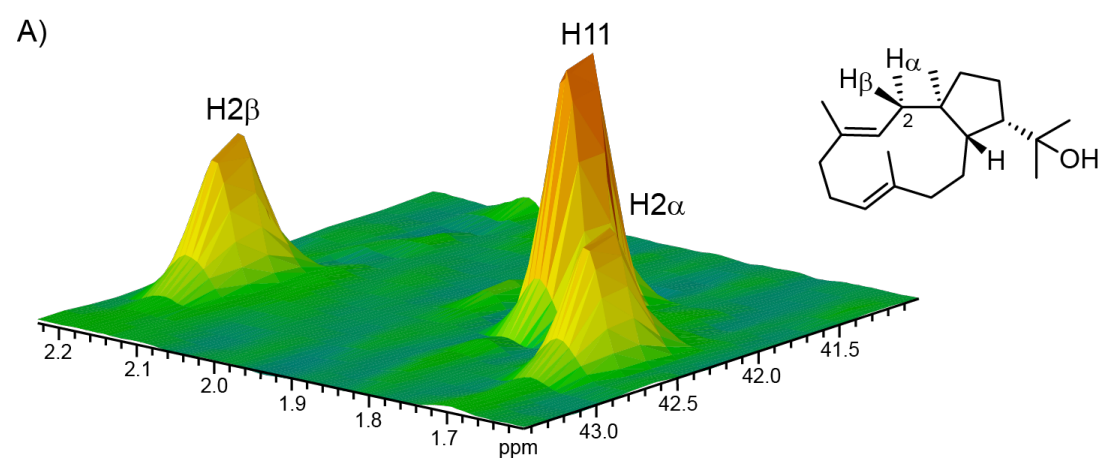

B)

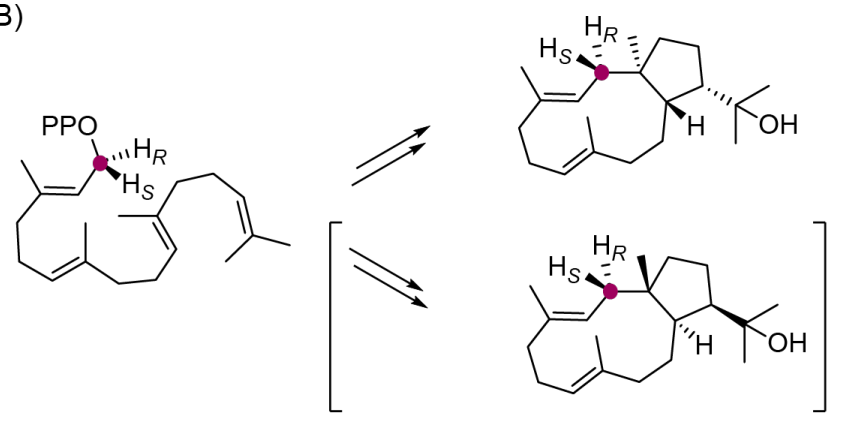

C)

$\mathrm{H} 2 \beta$

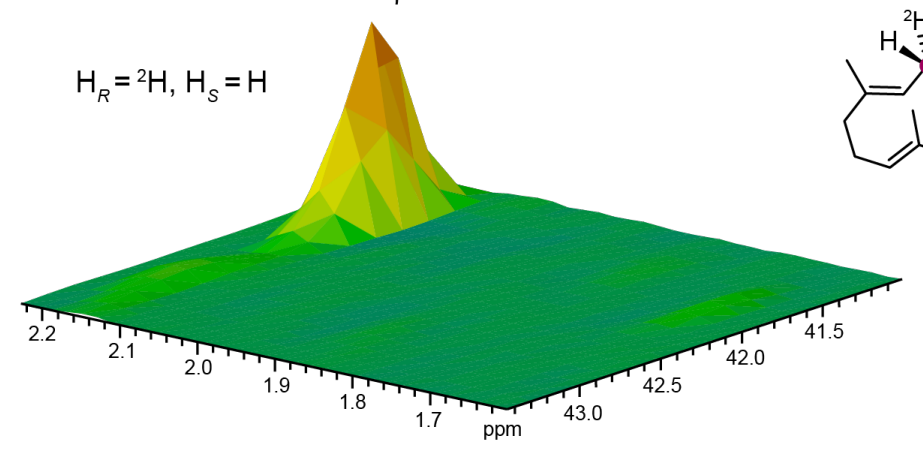

D)

$H 2 \alpha$<smiles>CC1=C2C(=CCC1)CC[C@H]1[C@@H](C(C)(C)O)CC[C@H]1[C@H]2C</smiles>

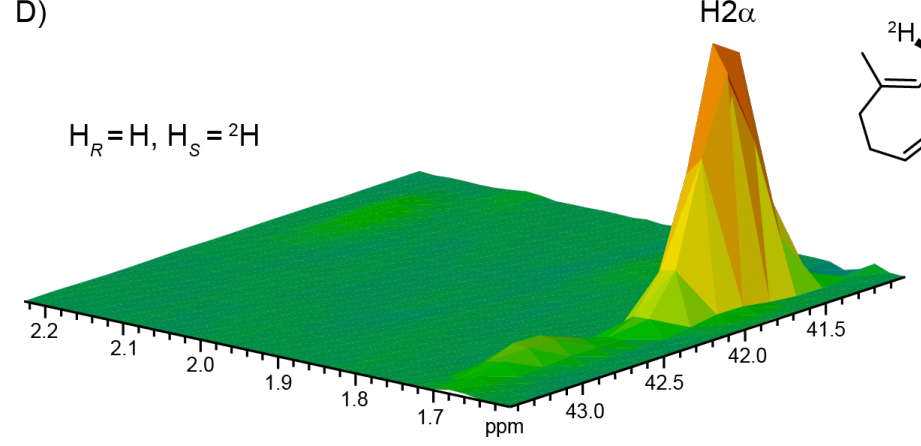

Figure 2: Determination of the absolute configuration of 3. (A) Partial HSQC spectrum of unlabelled $\mathbf{3}$ showing the region for $\mathrm{C} 2$, (B) cyclisation of GGPP to the two possible enantiomers of 3, (C) partial HSQC spectrum of the product obtained from $(R)-\left(1-{ }^{13} \mathrm{C}, 1-{ }^{2} \mathrm{H}\right) \mathrm{GGPP}$, and

(D) partial HSQC spectrum of the product obtained from $(S)-\left(1-{ }^{13} \mathrm{C}, 1-{ }^{2} \mathrm{H}\right) \mathrm{GGPP}$. Purple dots indicate ${ }^{13} \mathrm{C}$-labelled carbons. 
3 as reported for several other terpene synthases [13,20-22], these findings point to the absolute configuration of $(1 R, 3 E, 7 E, 11 S, 12 S)$-18-hydroxydolabella-3,7-diene.

For the incubation experiments with $(R)$ - and $(S)-\left(1-{ }^{13} \mathrm{C}, 1-\right.$ $\left.{ }^{2} \mathrm{H}\right) \mathrm{GPP}$, the terpene monomer IPP, HdS and the GGPP synthase (GGPPS) from $S$. cyaneofuscatus [12] were added to the reaction mixtures for an enzymatic elongation of the GPP isotopomers to the corresponding GGPPs. It is well established that the elongations of oligoprenyl diphosphates with IPP by type I oligoprenyl diphosphate synthases proceeds with inversion of configuration at $\mathrm{C} 1[23,24]$. The conversion of the obtained labelled GGPPs by HdS gave a stereospecific incorporation of the deuterium labelling into $\mathrm{H} 10 \alpha$ from $(R)-\left(1-{ }^{13} \mathrm{C}, 1-\right.$ $\left.{ }^{2} \mathrm{H}\right) \mathrm{GPP}$ and into $\mathrm{H} 10 \beta$ from $(S)-\left(1-{ }^{13} \mathrm{C}, 1-{ }^{2} \mathrm{H}\right) \mathrm{GPP}$ (Figure 3 ), which pointed to the same absolute configuration for $\mathbf{3}$ as

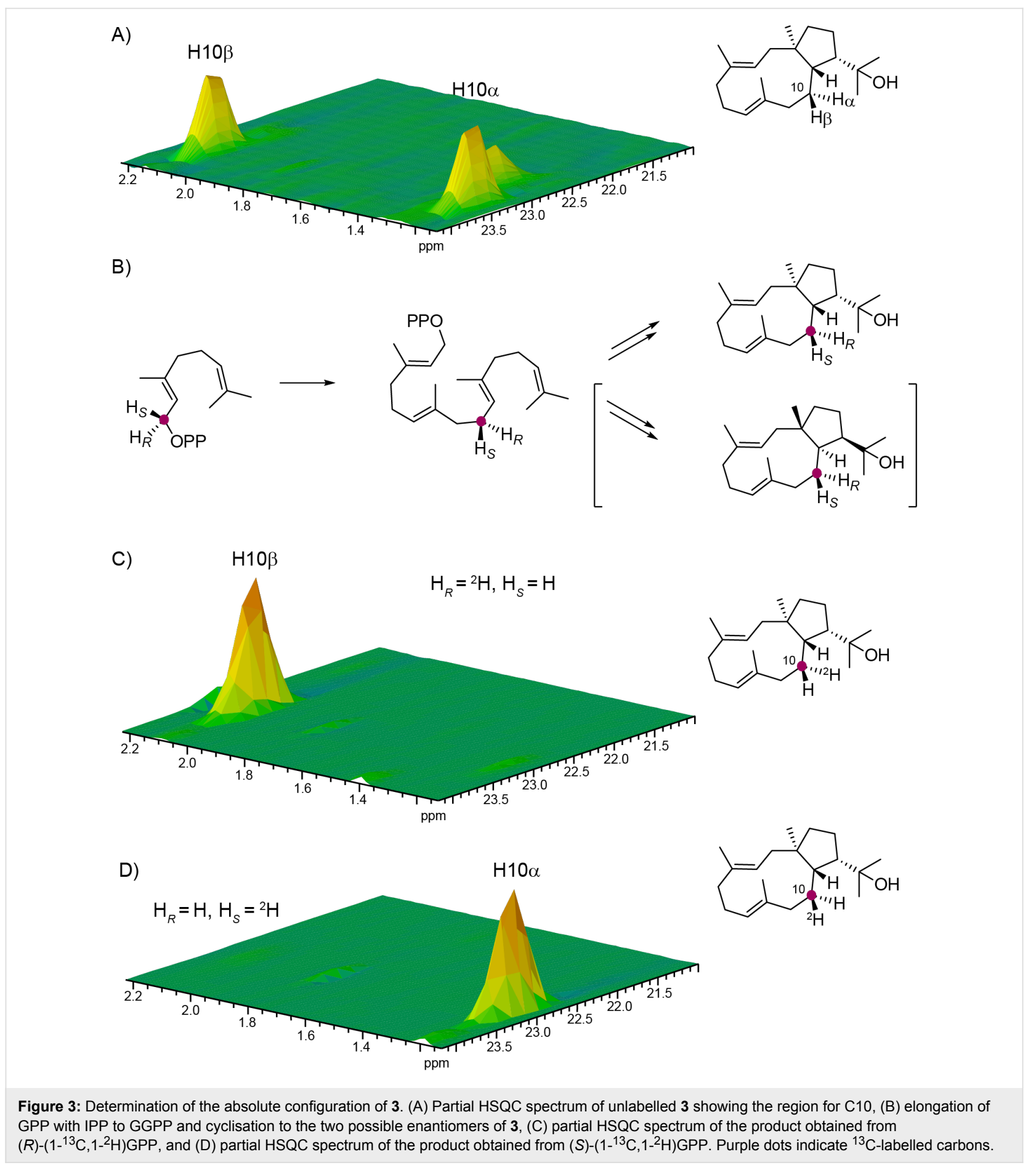


deduced from the experiments with the two enantiomers of $\left(1-{ }^{13} \mathrm{C}, 1-{ }^{2} \mathrm{H}\right) \mathrm{GGPP}$.

Similar incubation experiments were performed with $(R)$ - and $(S)-\left(1-{ }^{13} \mathrm{C}, 1-{ }^{2} \mathrm{H}\right) \mathrm{FPP}$, IPP, GGPPS and HdS, resulting in the stereospecific incorporation of deuterium labelling into the hydrogens at C6 of 3 (Figure 4). These experiments could not be used to confirm the absolute configuration of the diterpene, because the signals for H6 $\alpha$ and H6 $\beta$ could not be unambiguously assigned from the NMR spectra of the unlabelled com-

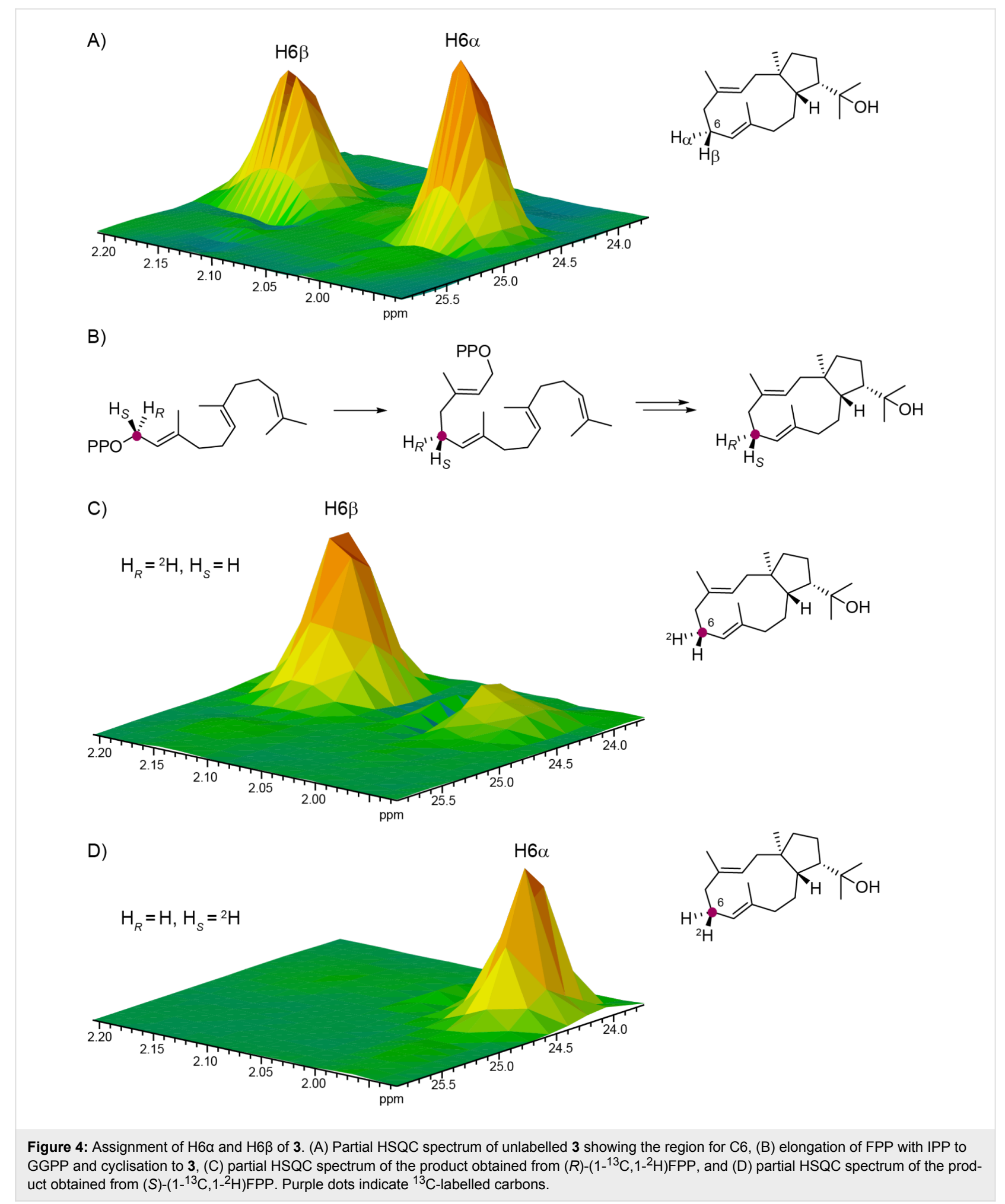


pound. Instead, the results from these incubation experiments were used for this assignment.

HdS exhibited a defined stereochemical course with respect to the methyl groups in the hydroxyisopropyl group of $\mathbf{3}$, as was indicated by conversion of $\left(12-{ }^{13} \mathrm{C}\right) \mathrm{FPP}$ and $\left(13-{ }^{13} \mathrm{C}\right) \mathrm{FPP}$ [25] with IPP by GGPPS and HdS that resulted in the specific incorporation of labelling into the carbon atoms absorbing at $30.8 \mathrm{ppm}$ and $30.7 \mathrm{ppm}$, respectively (Figure 5).

\section{Functional characterisation of bacterial diterpene synthase in planta}

To test the catalytic activity of HdS in planta, its corresponding gene was transiently expressed in $N$. benthamiana. Since we have shown before that the mitochondria are a suitable subcellular compartment for the heterologous production of terpenes [26], and it is known that one of the multiple GGPP synthases in plants are targeted to the mitochondria [27], we decided to attempt the expression of HdS with mitochondrial targeting (HdS-mit). A construct without targeting signal (HdS; resulting in cytoplasmic localisation) and an empty vector were used as controls. A p19 construct [28] was co-infiltrated in all treatments to suppress endogenous silencing of $N$. benthamiana upon agroinfiltration. No difference was found by GC-MS in EtOAc extracts of $N$. benthamiana leaves expressing an empty vector or HdS, while the chromatogram of an extract obtained from HdS-mit expressing leaves revealed an additional major compound (Figure 6). This compound (retention time of $21.08 \mathrm{~min}$ ) was identified as 18-hydroxydolabella-3,7-diene by GC-MS, using the diterpene alcohol obtained by the in vitro incubations of GGPP with HdS as an authentic standard. A preparative scale isolation of $\mathbf{3}$ from plant leaves expressing HdS-mit yielded $26.2 \mathrm{mg}$ of the pure diterpene alcohol from $100 \mathrm{~g}$ of fresh leaves $(0.03 \%$ of fresh leaf weight $)$. The obtained material was identical to 3 obtained by in vitro incubation of GGPP with recombinant $\mathrm{HdS}$ by ${ }^{1} \mathrm{H}$ and ${ }^{13} \mathrm{C}$ NMR spectroscopy.

A compound with the same structure as determined from our experiments for $(1 R, 3 E, 7 E, 11 S, 12 S)$-18-hydroxydolabella-3,7diene (3), but with different NMR data, was recently reported from the brown alga Dilophus spiralis [29]. In this study, a revision for the previously reported structure of $(1 S, 3 E, 7 E, 11 R, 12 S)$-18-hydroxydolabella-3,7-diene (1,11-diepi-3) for a compound isolated from the brown alga Dictyota dichotoma [30] was suggested (Scheme 2C). The same natural

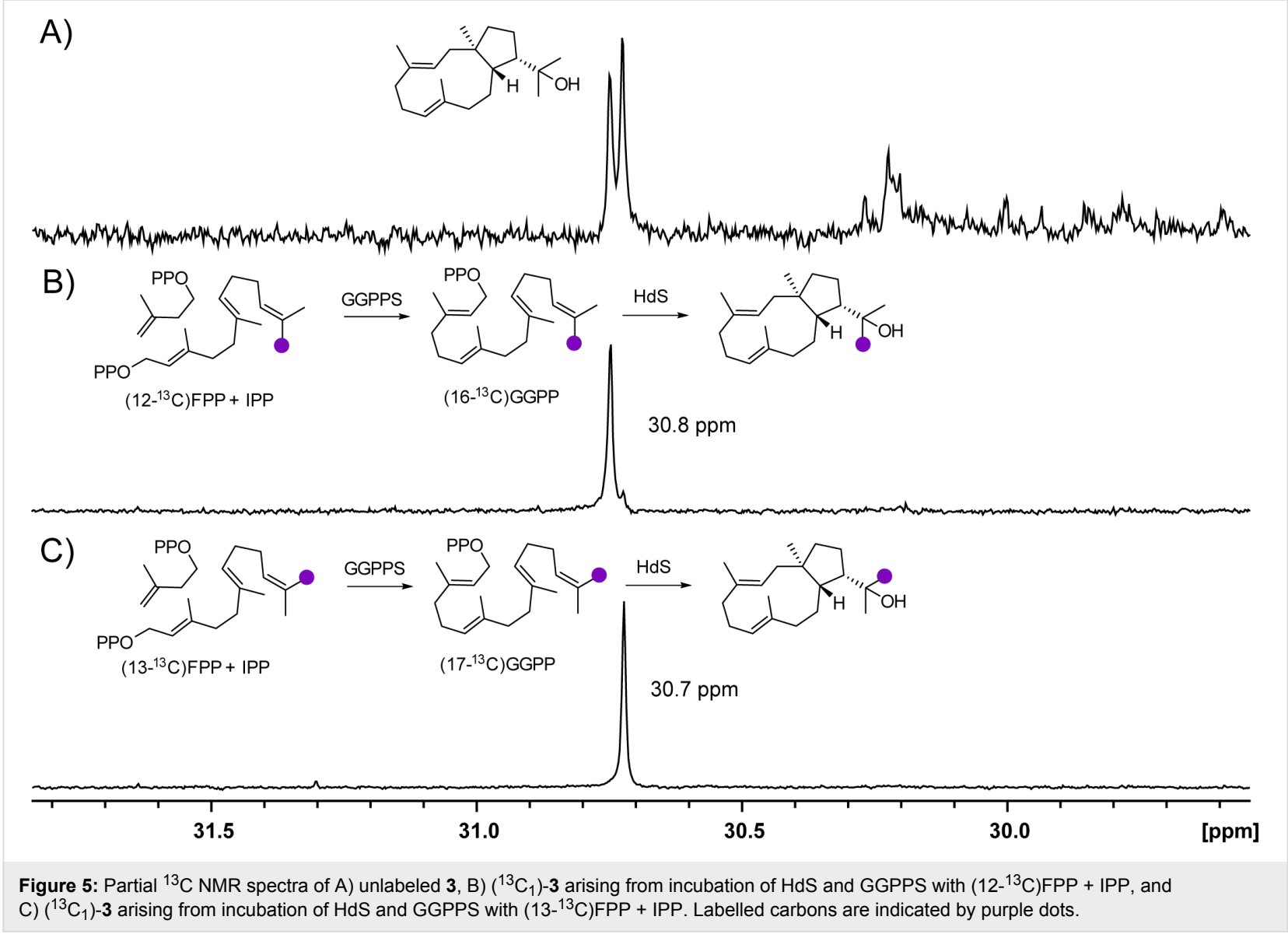




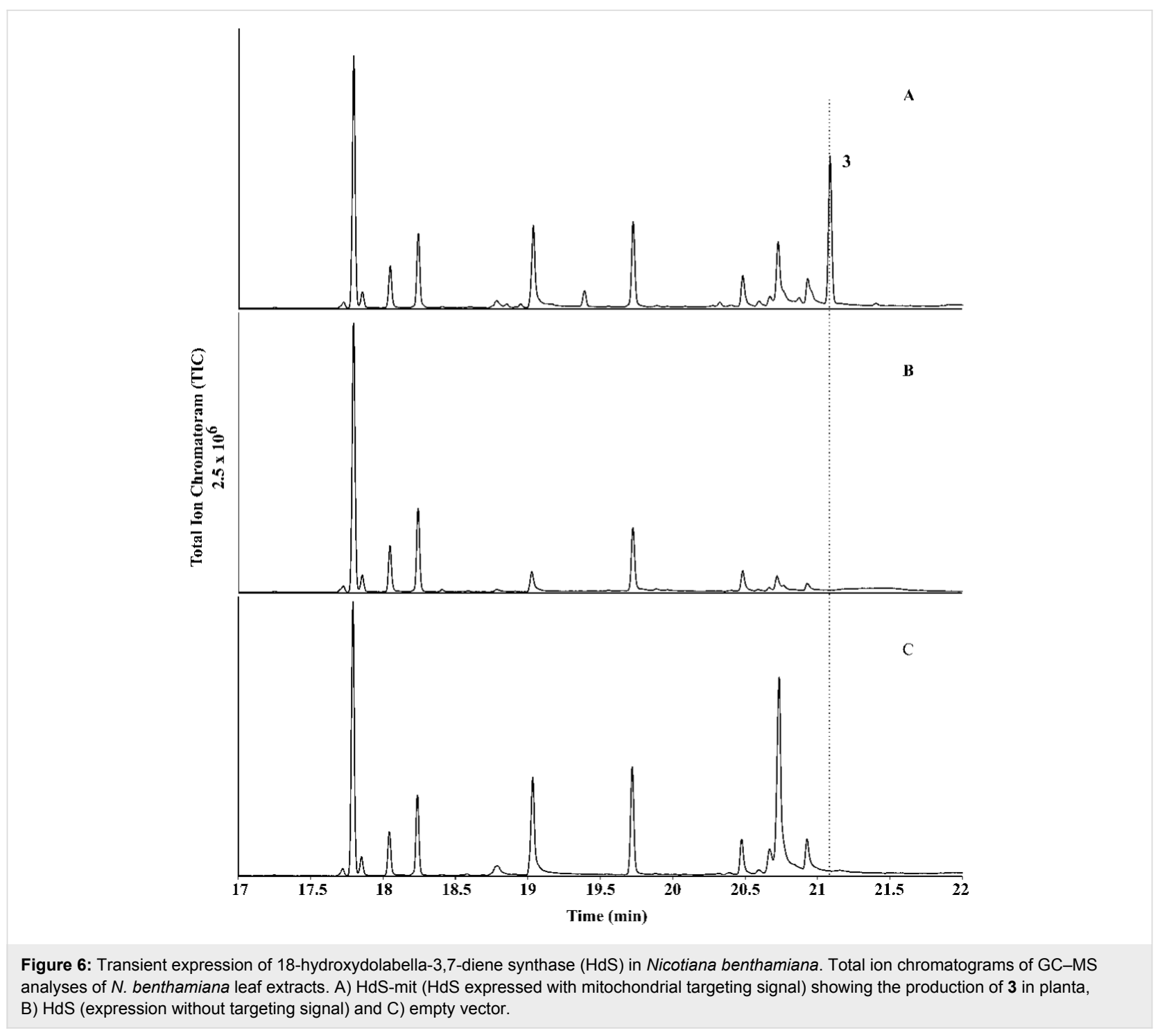

product is known from the higher plant Aglaia odorata [31], but in this case the reason for the assignment of the reported absolute configuration is unclear, because no optical rotation has been included in this study. It is difficult to judge what the correct structure for the compounds isolated from the brown algae and from $A$. odorata is, but the NMR data and isotopic labelling experiments presented here clearly point to the structure of $\mathbf{3}$ for the material obtained by us from the diterpene synthase from C. pinensis.

\section{Conclusion}

In this study we have reinvestigated a terpene synthase from Chitinophaga pinensis that was previously characterised as germacrene A synthase by heterologous expression in E. coli. While this result could be reproduced during the course of the present study, the recombinant purified enzyme surprisingly only showed diterpene synthase activity (it did not produce any product from GPP nor FPP) and the obtained product was identified as $(1 R, 3 E, 7 E, 11 S, 12 S)$-18-hydroxydolabella-3,7-diene. Notably, heterologous expression in the plant Nicotiana benthamiana and targeting to the mitochondria resulted in the production of the same diterpene alcohol. Although the mitochondria of $N$. benthamiana also produce FPP [32], again no germacrene $\mathrm{D}$ was detected. Taken together, these experiments demonstrate that the expression of one and the same terpene synthase in different organisms may lead to the formation of different products and even an altered substrate specificity. Indeed, it has been shown before that small alterations in the conditions such as a change of the metal cofactor can result in a switch from FPP to GPP synthase activity for an oligoprenyl diphosphate synthase from the beetle Phaedon cochleariae [33]. Similar small changes of the conditions, e.g., of the $\mathrm{pH}$ or the presence of different metal cofactors, may also change the product profile of a terpene synthase in different heterologous hosts. 
Changes in the product profile of terpene synthases depending on the host that was used to express the gene have been reported by Ginglinger et al., who have shown that Arabidopsis TPS10 produced mainly linalool when expressed in yeast and $N$. benthamiana, while the E. coli expressed protein catalysed the formation of mainly $\beta$-myrcene and $\beta$-ocimene [34]. The authors suggested different cofactor availabilities and biochemical conditions in the different hosts as the reason for their findings. Also Fischer et al. pointed out the effect that the host can have on the product specificity of terpene synthases [35]. In this context substrate availability is another issue to be considered: While no GGPP synthase is known in E. coli, this diterpene precursor is produced in the mitochondria of $N$. benthamiana. The yield of 18-hydroxydolabella-3,7-diene in planta of $26.2 \mathrm{mg}$ per $100 \mathrm{~g}$ of fresh leaves is useful for the preparative scale production of the diterpene alcohol that can easily be isolated by extraction and column chromatography, which underpins the potential of plants, besides the recently reviewed microbial hosts for the sustainable production of diterpenes [36], as expression systems for secondary metabolite genes. The function of the investigated terpene synthase from $C$. pinensis in its natural context remains elusive, since neither $(1 R, 3 E, 7 E, 11 S, 12 S)$-18-hydroxydolabella-3,7-diene nor germacrene $A$ or its Cope rearrangement product $\beta$-elemene could be detected in laboratory cultures [37].

\section{Supporting Information}

\section{Supporting Information File 1}

Experimental details for gene expression and enzyme incubation experiments, NMR spectra of

$(1 R, 3 E, 7 E, 11 S, 12 S)$-18-hydroxydolabella-3,7-diene, and heterologous expression in Nicotiana benthamiana. [http://www.beilstein-journals.org/bjoc/content/ supplementary/1860-5397-13-171-S1.pdf]

\section{Acknowledgements}

This work was funded by the DFG (DI1536/7-1) and by the Fonds der Chemischen Industrie.

\section{References}

1. Croteau, R.; Felton, N. M.; Wheeler, C. J. J. Biol. Chem. 1985, 260, 5956-5962.

2. Cane, D. E.; Swanson, S.; Murthy, P. P. N. J. Am. Chem. Soc. 1981, 103, 2136-2138. doi:10.1021/ja00398a063

3. Cane, D. E.; Pargellis, C. Arch. Biochem. Biophys. 1987, 254, 421-429. doi:10.1016/0003-9861(87)90120-2

4. Rabe, P.; Rinkel, J.; Nubbemeyer, B.; Köllner, T. G.; Chen, F.; Dickschat, J. S. Angew. Chem., Int. Ed. 2016, 55, 15420-15423. doi:10.1002/anie.201608971
5. Chen, X.; Köllner, T. G.; Jia, Q.; Norris, A.; Santhanham, B.; Rabe, P.; Dickschat, J. S.; Shaulsky, G.; Gershenzon, J.; Chen, F. Proc. Natl. Acad. Sci. U. S. A. 2016, 113, 12132-12137. doi:10.1073/pnas.1610379113

6. Dickschat, J. S. Nat. Prod. Rep. 2016, 33, 87-110. doi:10.1039/C5NP00102A

7. Rabe, P.; Rinkel, J.; Klapschinski, T. A.; Barra, L.; Dickschat, J. S. Org. Biomol. Chem. 2016, 14, 158-164. doi:10.1039/C5OB01998B

8. Schifrin, A.; Khatri, Y.; Kirsch, P.; Thiel, V.; Schulz, S.; Bernhardt, R. Org. Biomol. Chem. 2016, 14, 3385-3393. doi:10.1039/C6OB00130K

9. Klapschinski, T. A.; Rabe, P.; Dickschat, J. S. Angew. Chem., Int. Ed. 2016, 55, 10141-10144. doi:10.1002/anie.201605425

10. Rabe, P.; Schmitz, T.; Dickschat, J. S. Beilstein J. Org. Chem. 2016, 12, 1839-1850. doi:10.3762/bjoc.12.173

11. Rinkel, J.; Rabe, P.; Garbeva, P.; Dickschat, J. S. Angew. Chem., Int. Ed. 2016, 55, 13593-13596. doi:10.1002/anie.201608042

12. Rabe, P.; Rinkel, J.; Dolja, E.; Schmitz, T.; Nubbemeyer, B.; Luu, T. H.; Dickschat, J. S. Angew. Chem., Int. Ed. 2017, 56, 2776-2779. doi:10.1002/anie.201612439

13. Rabe, P.; Samborskyy, M.; Leadlay, P. F.; Dickschat, J. S. Org. Biomol. Chem. 2017, 15, 2353-2358. doi:10.1039/C7OB00234C

14. Rinkel, J.; Rabe, P.; Chen, X.; Köllner, T. G.; Chen, F.; Dickschat, J. S. Chem. - Eur. J. 2017, 23, 10501-10505. doi:10.1002/chem.201702704

15. Yamada, Y.; Kuzuyama, T.; Komatsu, M.; Shin-ya, K.; Omura, S.; Cane, D. E.; Ikeda, H. Proc. Natl. Acad. Sci. U. S. A. 2015, 112, 857-862. doi:10.1073/pnas.1422108112

16. Yamada, Y.; Arima, S.; Nagamitsu, T.; Johmoto, K.; Uekusa, H.; Eguchi, T.; Shin-ya, K.; Cane, D. E.; Ikeda, H. J. Antibiot. 2015, 68, 385-394. doi:10.1038/ja.2014.171

17. Rabe, P.; Dickschat, J. S. Angew. Chem., Int. Ed. 2013, 52 , 1810-1812. doi:10.1002/anie.201209103

18. Dickschat, J. S.; Pahirulzaman, K. A. K.; Rabe, P.; Klapschinski, T. A. ChemBioChem 2014, 15, 810-814. doi:10.1002/cbic.201300763

19. de Kraker, J.-W.; Franssen, M. C. R.; de Groot, A.; König, W. A.; Bouwmeester, H. J. Plant Physiol. 1998, 117, 1381-1392. doi:10.1104/pp.117.4.1381

20. Cane, D. E.; Oliver, J. S.; Harrison, P. H. M.; Abell, C.; Hubbard, B. R.; Kane, C. T.; Lattman, R. J. Am. Chem. Soc. 1990, 112, 4513-4524. doi:10.1021/ja00167a059

21. Cane, D. E.; Prabhakaran, P. C.; Salaski, E. J.; Harrison, P. H. M.; Noguchi, H.; Rawlings, B. J. J. Am. Chem. Soc. 1989, 111, 8914-8916. doi:10.1021/ja00206a022

22. Wang, C.-M.; Hopson, R.; Lin, X.; Cane, D. E. J. Am. Chem. Soc. 2009, 131, 8360-8361. doi:10.1021/ja9021649

23. Cornforth, J. W.; Cornforth, R. H.; Donninger, C.; Popjak, G. Proc. R. Soc. London, Ser. B 1966, 163, 492-514. doi:10.1098/rspb.1966.0004

24. Thulasiram, H. V.; Poulter, C. D. J. Am. Chem. Soc. 2006, 128, 15819-15823. doi:10.1021/ja065573b

25. Rabe, P.; Barra, L.; Rinkel, J.; Riclea, R.; Citron, C. A.; Klapschinski, T. A.; Janusko, A.; Dickschat, J. S. Angew. Chem., Int. Ed. 2015, 54, 13448-13451. doi:10.1002/anie.201507615

26. Liu, Q.; Majdi, M.; Cankar, K.; Goedbloed, M.; Charnikhova, T.; Verstappen, F. W. A.; de Vos, R. C. H.; Beekwilder, J.; van der Krol, S.; Bouwmeester, H. J. PLoS One 2011, 6, e23255. doi:10.1371/journal.pone.0023255

27. Okada, K.; Saito, T.; Nakagawa, T.; Kawamukai, M.; Kamiya, Y. Plant Physiol. 2000, 122, 1045-1056. doi:10.1104/pp.122.4.1045 
28. Voinnet, O.; Rivas, S.; Mestre, P.; Baulcombe, D. Plant J. 2003, 33, 949-956. doi:10.1046/j.1365-313X.2003.01676.x

29. Ioannou, E.; Quesada, A.; Rahman, M. M.; Gibbons, S.; Vagias, C.; Roussis, V. J. Nat. Prod. 2011, 74, 213-222. doi:10.1021/np1006586

30. Amico, V.; Currenti, R.; Oriente, G.; Piattelli, M.; Tringali, C. Phytochemistry 1981, 20, 848-849. doi:10.1016/0031-9422(81)85196-5

31. Cai, X.-H.; Luo, X.-D.; Zhou, J.; Hao, X.-J. Helv. Chim. Acta 2005, 88, 2938-2943. doi:10.1002/hlca.200590236

32. Kappers, I. F.; Aharoni, A.; van Herpen, T. W. J. M.; Luckerhoff, L. L. P.; Dicke, M.; Bouwmeester, H. J. Science 2005, 309, 2070-2072. doi:10.1126/science.1116232

33. Frick, S.; Nagel, R.; Schmidt, A.; Bodemann, R. R.; Rahfeld, P.; Pauls, G.; Brandt, W.; Gershenzon, J.; Boland, W.; Burse, A. Proc. Natl. Acad. Sci. U. S. A. 2013, 110, 4194-4199. doi:10.1073/pnas.1221489110

34. Ginglinger, J. F.; Boachon, B.; Höfer, R.; Paetz, C.; Köllner, T. G.; Miesch, L.; Lugan, R.; Baltenweck, R.; Mutterer, J.; Ullmann, P.; Beran, F.; Claudel, P.; Verstappen, F.; Fischer, M. J. C.; Karst, F.; Bouwmeester, H.; Miesch, M.; Schneider, B.; Gershenzon, J.; Ehlting, J.; Werck-Reichhart, D. Plant Cell 2013, 25, 4640-4657. doi:10.1105/tpc.113.117382

35. Fischer, M. J. C.; Meyer, S.; Claudel, P.; Perrin, M.; Ginglinger, J. F.; Gertz, C.; Masson, J. E.; Werck-Reinhardt, D.; Hugueney, P.; Karst, F. J. Biotechnol. 2013, 163, 24-29. doi:10.1016/j.jbiotec.2012.10.012

36. Kemper, K.; Hirte, M.; Reinbold, M.; Fuchs, M.; Brück, T. Beilstein J. Org. Chem. 2017, 13, 845-854. doi:10.3762/bjoc.13.85

37. Citron, C. A.; Gleitzmann, J.; Laurenzano, G.; Pukall, R.; Dickschat, J. S. ChemBioChem 2012, 13, 202-214. doi:10.1002/cbic.201100641

\section{License and Terms}

This is an Open Access article under the terms of the Creative Commons Attribution License (http://creativecommons.org/licenses/by/4.0), which permits unrestricted use, distribution, and reproduction in any medium, provided the original work is properly cited.

The license is subject to the Beilstein Journal of Organic Chemistry terms and conditions:

(http://www.beilstein-journals.org/bjoc)

The definitive version of this article is the electronic one which can be found at: doi:10.3762/bjoc. 13.171 